\title{
Chapter 5 \\ The Influence of Socio-economic and Socio-demographic Factors in the Association Between Urban Green Space and Health
}

\author{
Nadja Kabisch
}

\begin{abstract}
Green spaces can help preventing potential negative health outcomes from climate change and urbanisation. Urban green spaces may reduce cardiovascular diseases exaggerated by heat stress or noise because of their climate regulation and noise-buffering potential. Urban green space may also promote physical activity and social interactions, and thus improve the physical and mental health of residents who tend to be more stressed in urban environments. Research findings on associations between urban green space and health outcomes are, however, not consistent, and potential relationships are often affected by confounding factors. In this chapter, a systematic review of the association between urban green space and health is presented, with a particular focus on socio-economic and sociodemographic confounders that may over-ride potential associations. Results show that there is some positive effect of urban green space on mental health and cardiovascular diseases. However, evidence is weak as many other studies show that socio-economic confounders, such as household income or neighbourhood deprivation, have the highest impact. The mediating effect of urban green space to decrease health inequality among different socio-economic groups may be more important. Based on the results of the review, conclusions are drawn on how to design green space that is beneficial for the health and well-being of all population groups including the vulnerable groups of children, the elderly and deprived people. This field of research is growing, and important prospects for future research on urban green and health are highlighted.
\end{abstract}

Keywords Green space $\cdot$ Urban $\cdot$ Health $\cdot$ Well-being $\cdot$ Confounder

\footnotetext{
N. Kabisch $(\bowtie)$

Department of Geography, Humboldt-Universität zu Berlin, Berlin, Germany

e-mail: nadja.kabisch@geo.hu-berlin.de
} 


\section{Highlights}

- A systematic review of the association between urban green space and health is presented.

- The focus has been on socio-economic and socio-demographic confounders.

- Results show some positive association between urban green space, mental health and cardiovascular diseases.

- Evidence is rather weak, and socio-economic confounders have the highest impact on health outcome effects.

- The mediating effect of urban green space to decrease health inequality among different socio-economic groups may be more important.

\subsection{Introduction}

The value of urban nature has been considered within a range of societal challenge areas in cities, such as water management, air quality, urban biodiversity, and human health and well-being (Raymond et al. 2017). Assessments of these values - mostly using the ecosystem services (ESS) concept - are now informing urban policy and planning across the world. For example, at the international level, the Intergovernmental Panel on Biodiversity and Ecosystem Services discusses the benefits of nature for people as one way to promote nature's values in environmental decision-making, for example, through the ESS concept and other human-nature inter-relations (Díaz et al. 2018). The integrated view to sustainable urban development is also highlighted in the 2030 Agenda for Sustainable Development and its sustainable development goals (SDGs), the New Urban Agenda adopted at the United Nations' HABITAT III conference and promoted by the European Commission's research and innovation policy on nature-based solutions. In particular, Goal 11 of the SDGs underlines that "Making cities safe and sustainable [...] involves $[\ldots]$ creating green public spaces, and improving urban planning and management in a way that is both participatory and inclusive" (The United Nations Development Programme (UNDP) 2015). Urban green spaces such as parks, allotment gardens, street trees, urban gardens, cemeteries, green roofs and green facades were shown to increase sustainability in urban areas. Urban green spaces ameliorate high temperatures in cities (Bowler et al. 2010), reduce noise, help filter pollutants from the air, and improve water inflow in times of extreme precipitation events (Haase et al. 2014). When developing new green spaces to make cities (more) sustainable, a key component for urban planning is to consider the spatial location of urban green spaces within the urban area, in order to understand their potential role in mediating improved health outcomes for groups of people.

Interest in research has recently increased regarding the role that urban green spaces may play in improving the health of urban residents (Hartig et al. 2014). One aspect that has been discussed is whether urban green can act as a health promoter by encouraging more active lifestyles, or as a disease preventer through reducing the impact of negative environmental conditions such as extreme weather events, air pollution, noise or heat (Kabisch et al. 2017; van den Bosch and Ode Sang 2017). 
The reduction of the impact of negative environmental conditions is hypothesised to occur through providing ecosystem services, as presented above. In particular, van den Bosch and Ode Sang (2017) showed that urban green space contributes to the health of city residents by decreasing all-cause and cardiovascular disease-related mortality, adverse birth outcomes and mental disorders, particularly through providing regulating and provisioning ESS and through cultural ESS linked to sociobehavioural pathways. The authors, however, did not find significant results for sufficient evidence for stress reduction and physical activity as the mediating pathway.

They conclude that the impact of improving environmental conditions through urban green spaces is often spatially explicit, with an unequal distribution of environmental burdens and goods. In particular, disadvantaged and minority groups often bear higher environmental burdens such as noise or air pollution (Wolch et al. 2014), while they have less access to urban green spaces and the benefits they provide (Cook et al. Chap. 11, this volume). Clark et al. (2014) showed that low-income people are disproportionately exposed to air pollution in the USA, whereas Richardson et al. (2013) demonstrated a similar relationship for particular areas in Europe. Wolch et al. (2005) found that park availability is reduced in deprived neighbourhoods. Street trees, as a particular part of the green infrastructure network, have also been found to be differently distributed according to neighbourhood socio-economic status (Landry and Chakraborty 2009). Interestingly, Timperio et al. (2007) could not find any statistically significant relationship that urban green spaces are more scarce in low-income or minority neighbourhoods in Australia (Timperio et al. 2007). A recent review of park access by Rigolon (2016) also showed inconclusive findings for distance to parks but striking differences for size and quality of parks, with smaller park sizes and lower quality of parks for neighbourhoods of low socio-economic and minority groups. This suggests a more complex link between urban green space availability and accessibility and socio-economic differences, which depends on the indicators used for measuring greenness, availability and quality features of urban green spaces.

The relationships between environmental burdens, green space accessibility, socio-economic factors and potential health outcomes are still not clearly understood, and vary between studies. A structured systematic review is presented in this chapter to help close this gap in the research. In particular, effects of urban green spaces on urban health depending on accessibility and socio-economic status/trends are investigated. The term 'socio-economic confounder' is used in this chapter to describe factors that have a potential effect on health and that may even over-ride a potential association between urban green space and health outcomes.

\subsection{Methods}

A systematic, structured and quantitative literature review of peer-reviewed articles that were published in international scientific journals was conducted in November 2017. This review identified 140 papers of which the highest proportion were 


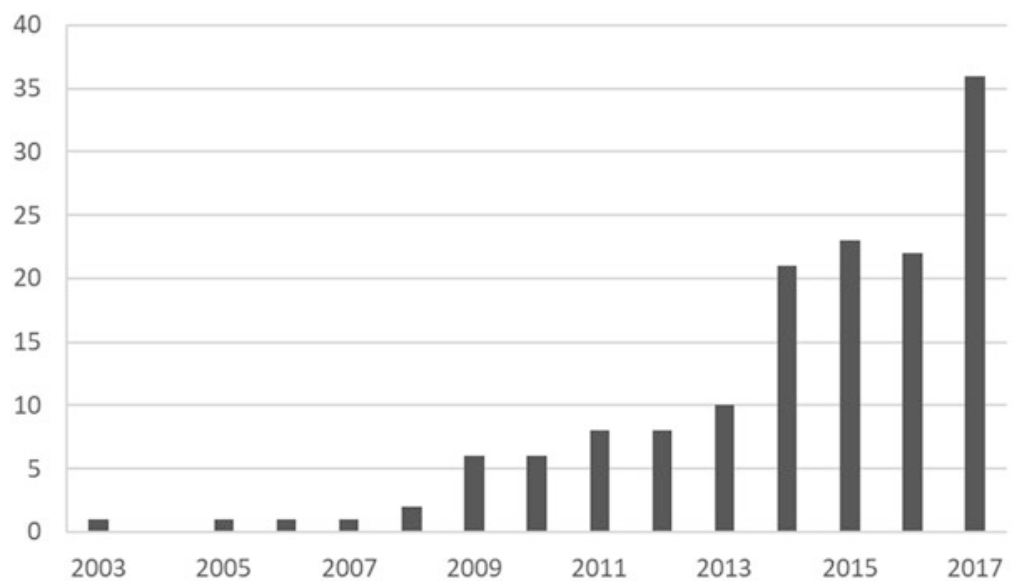

Fig. 5.1 Number of papers published in Web of Science on the relationship between urban green spaces and potential health effects

published within the last 5 years (2013-2017, Fig. 5.1). The analysis was therefore restricted to papers published in English from 2013 onward to highlight recent advances in the subject. Web of Knowledge ${ }^{\odot}$ was used as the scientific search engine to find appropriate articles. The search profile was based on a number of primary search terms related to particular categories related to the topic. The first main term related to the topic 'urban green', the second to 'availability' and 'access', the third to socio-economic and socio-demographic profile of neighbourhoods or affected populations, and included key search terms such as 'income', 'age' or 'class', and the fourth to health including terms such as 'health', 'disease' and 'well-being'. The respective terms were chosen based on the author's own experiences with the topic and other reviews, existing theories and initial literature studies that revealed some inconsistent relationships on the green space associability link. The operators AND between and OR within categories were used. It was decided to restrict the search to scientific peer-reviewed papers. Excluded from the literature search were research reports and other non-scientific publications or bibliographies. However, these were used in searches for additional literature as was done with other existing reviews that touched on the topic (Kabisch et al. 2017; van den Bosch and Ode Sang 2017). Articles found through the search strategy were screened and included in the final sample if the content matched the main research objectives. An article was evaluated as not relevant if no direct link to health outcomes related to urban green could be found, or when the article presented a method only as main content. This strategy resulted in a total of 25 papers. All final articles were analysed using a standardised data extraction sheet based on pre-defined questions for review. This included general information such as publication date, case-study location, respective scale of interest, particular assessment method or data used. 


\subsection{Results}

The relationship between urban green spaces and potential health effects is a growing research field, with an increasing number of publications, particularly since 2013 (Fig. 5.1). The research discussed here focusses on those studies that considered differences in the socio-economic and socio-demographic context of the population groups studied. In addition, the particular green space metrics, buffers and data used in the study are considered as it was assumed that there might be a difference in health outcome results when different measures are used. Only 25 papers were directly related to a health outcome linked to urban green space use or availability. The remaining papers indirectly address a health outcome by mentioning a potential health benefit of green space exposure for different population groups in the abstract but not analysing health outcome as a main aim. Papers that address health directly mostly deal with mental health outcomes followed by studies on physical activity, birth outcome, overweight, general health and cardiovascular diseases. Results are presented in Table 5.1 and summarised with main associations indicated in Fig. 5.4.

\subsubsection{Mental Health and General Health}

Cohen-Cline et al. (2015) studied potential associations between access to green space and self-reported depression, stress and anxiety. When adjusted for confounding factors such as income, the association between urban green space and less depression remained significant. Mukherjee et al. (2017) found a similar association between the nearest park size and depression even when controlling for confounders such as household wealth and education. They showed that a smaller size of the nearest park was associated with higher odds of depression. Controlling for socioeconomic status, Triguero-Mas et al. (2015) identified that surrounding green spaces were associated with better mental health. Mitchell et al. (2015) found improved mental health in lower income groups when access to green space and recreational areas improved. A similar relationship was found by Feda et al. (2015), who showed an inverse association between accessibility of urban parks and perceived stress among adolescents when controlled for socio-economic status. Thompson et al. (2016) identified that higher quantity and better access to green spaces including gardens and allotments were significantly related to decreased stress levels in deprived communities.

For 3- to 5-year-old children, Flouri et al. (2014) found that in lower income groups, children with a higher percentage of green space in their neighbourhood had fewer emotional problems. For a study of 4- to 6-year-old children, those with comparatively more park and natural area space around their homes had better mental health outcomes. Interestingly, Astell-Burt et al. (2014) showed that the green space-mental health association varies across the life course and between 


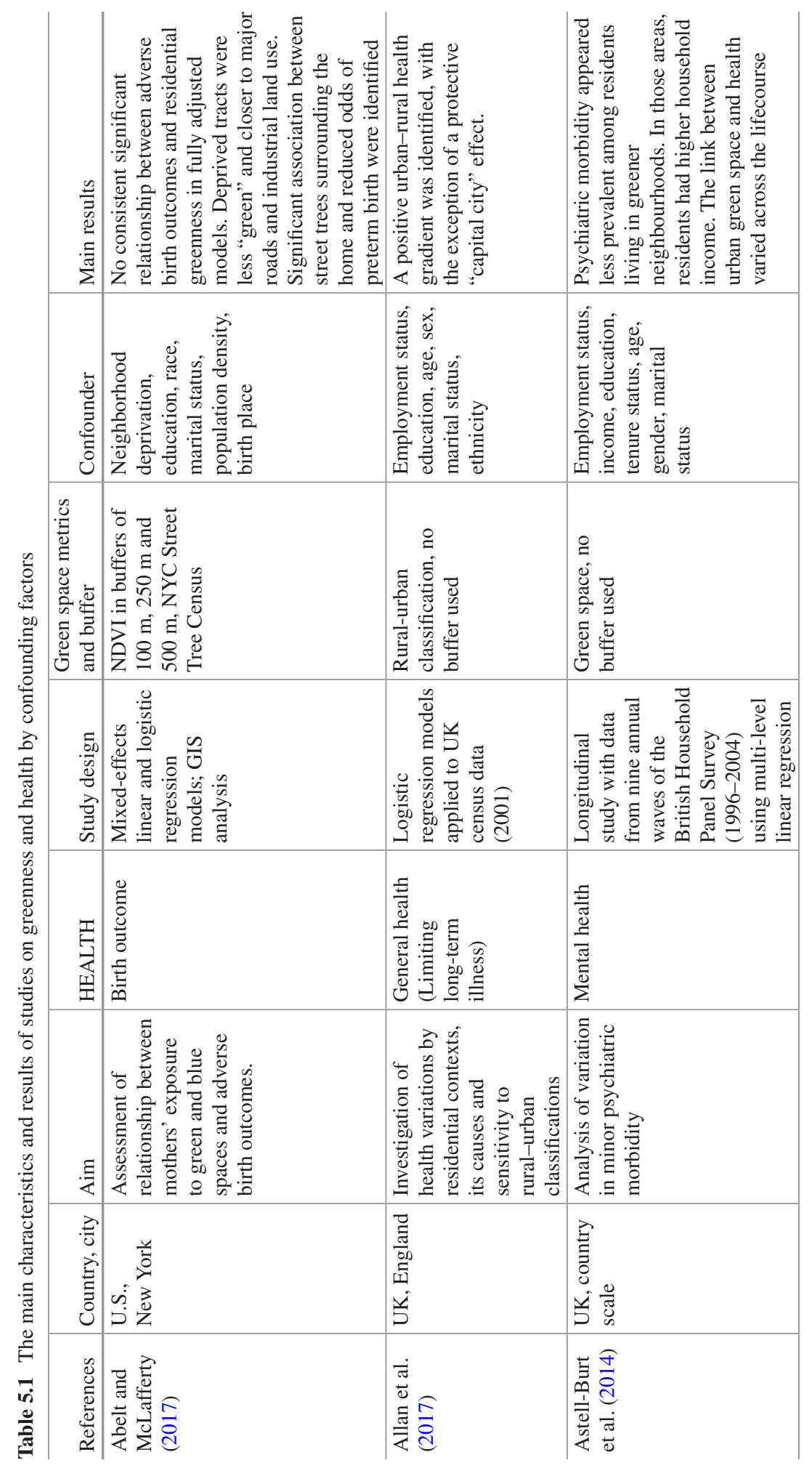




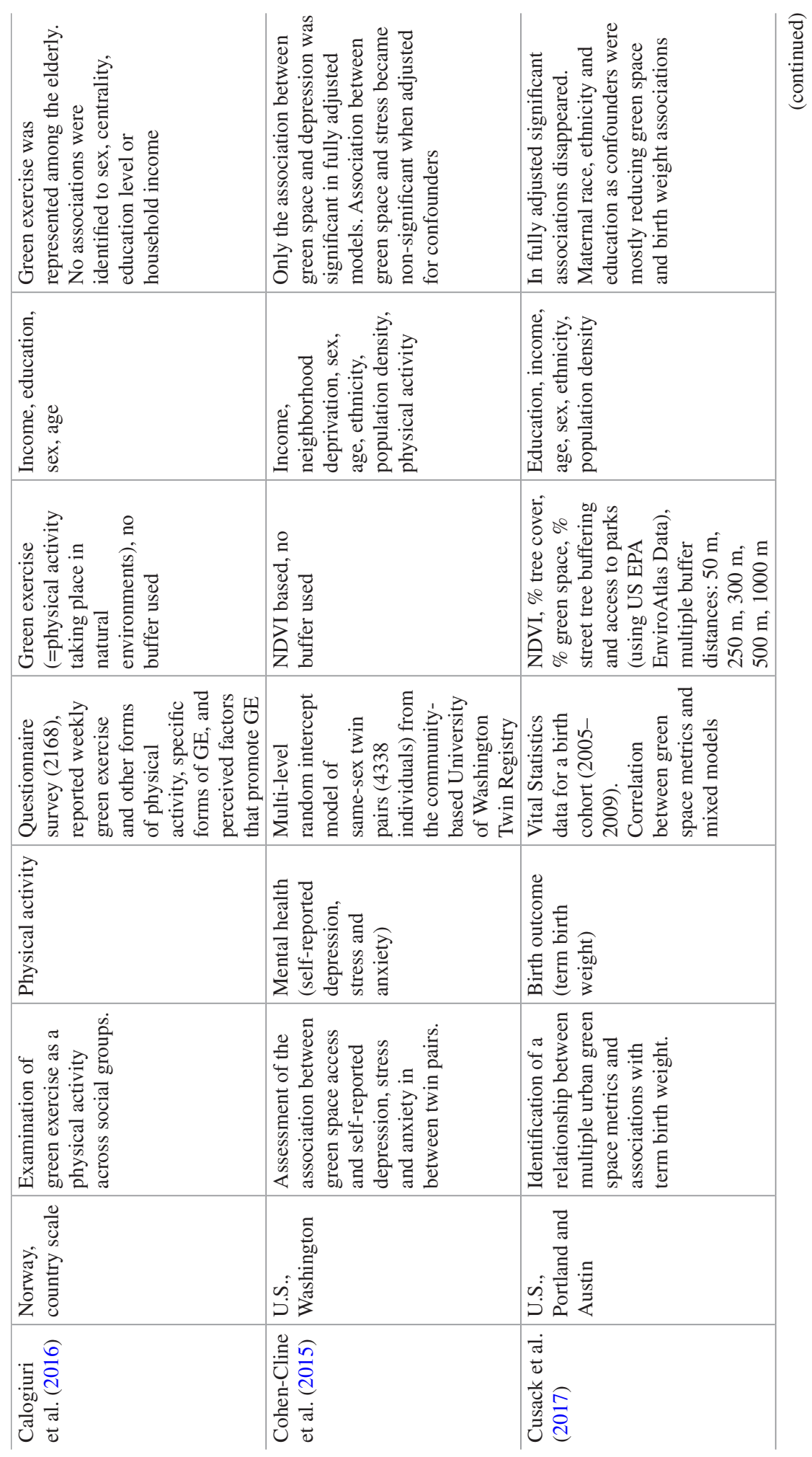




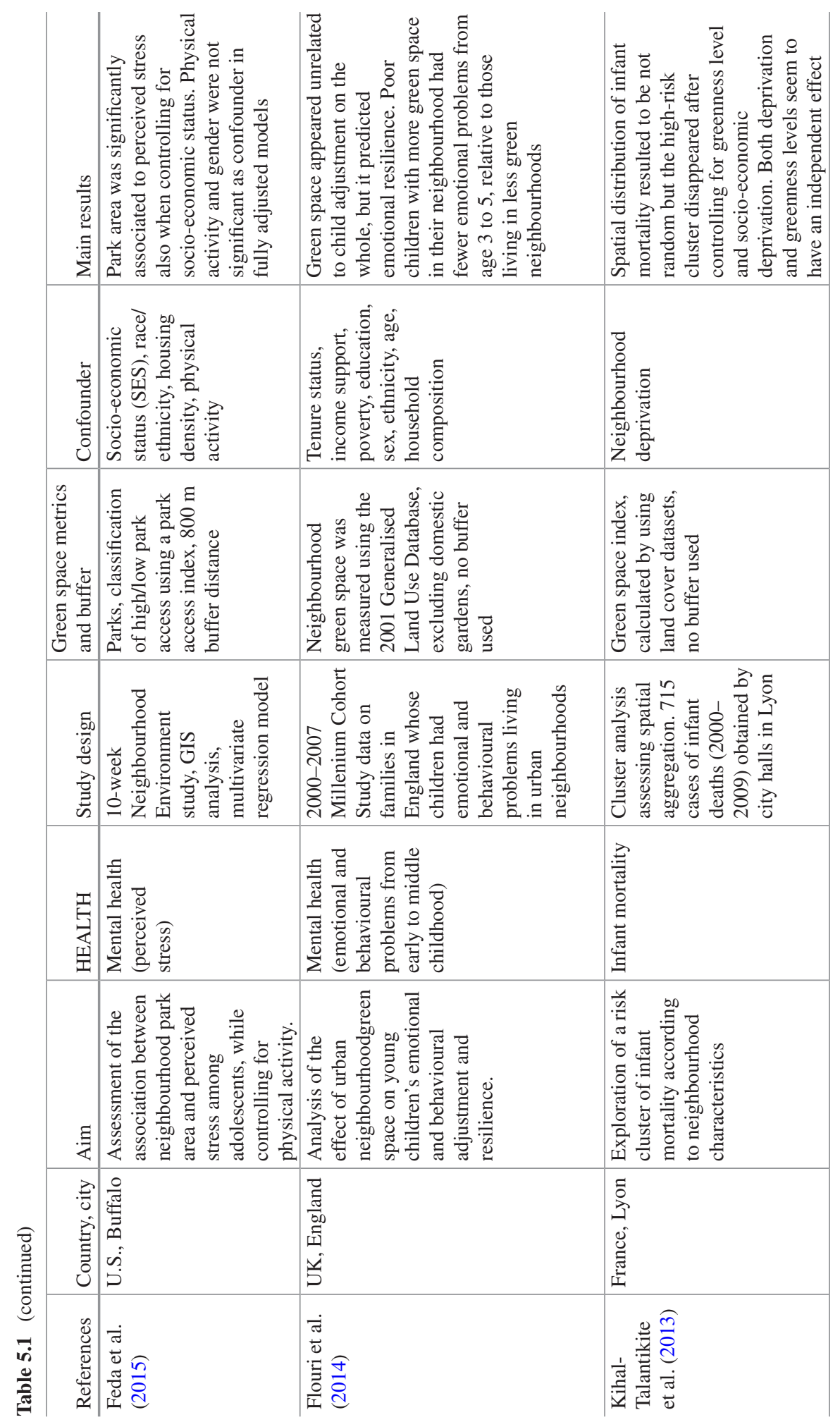




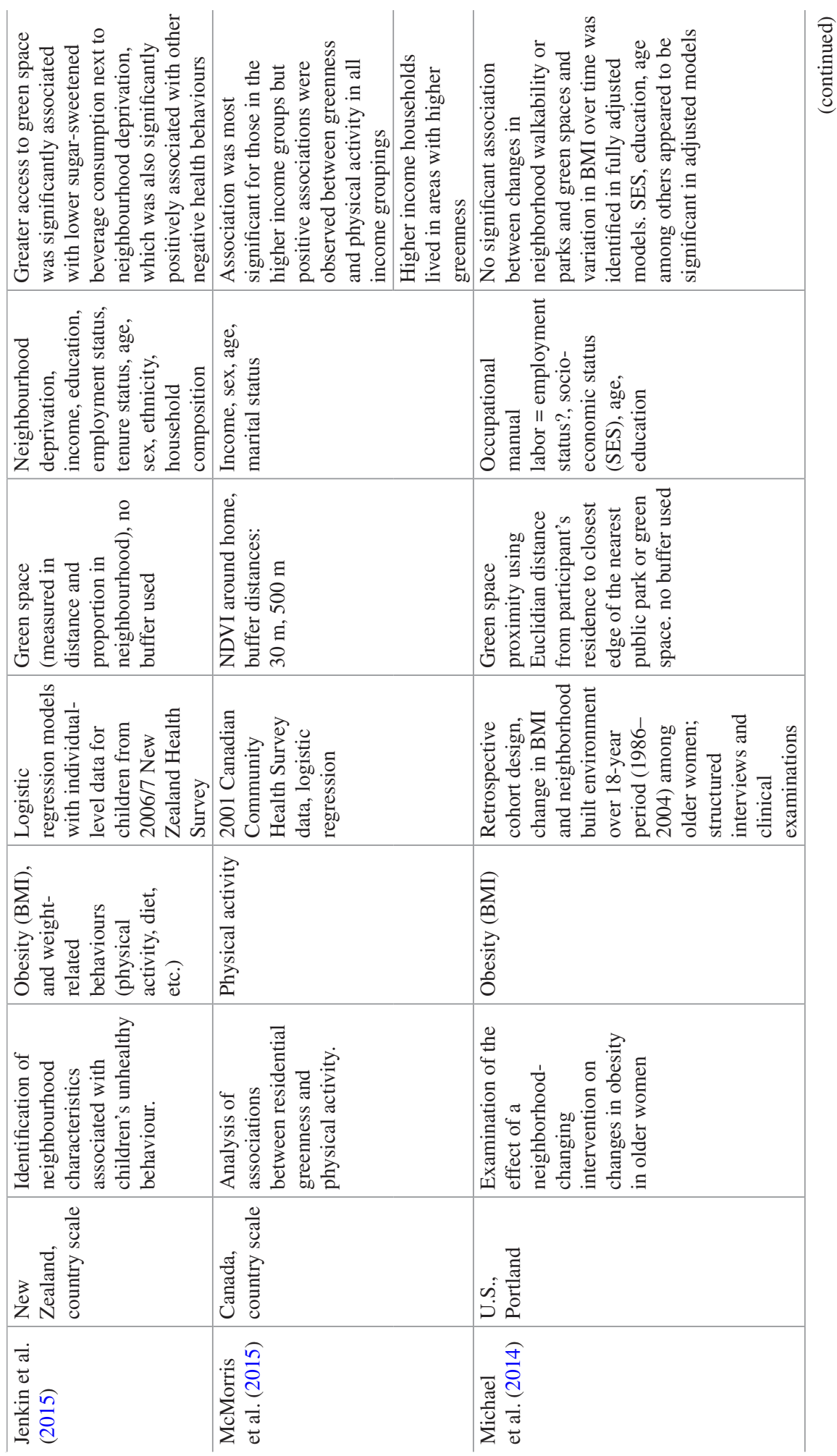




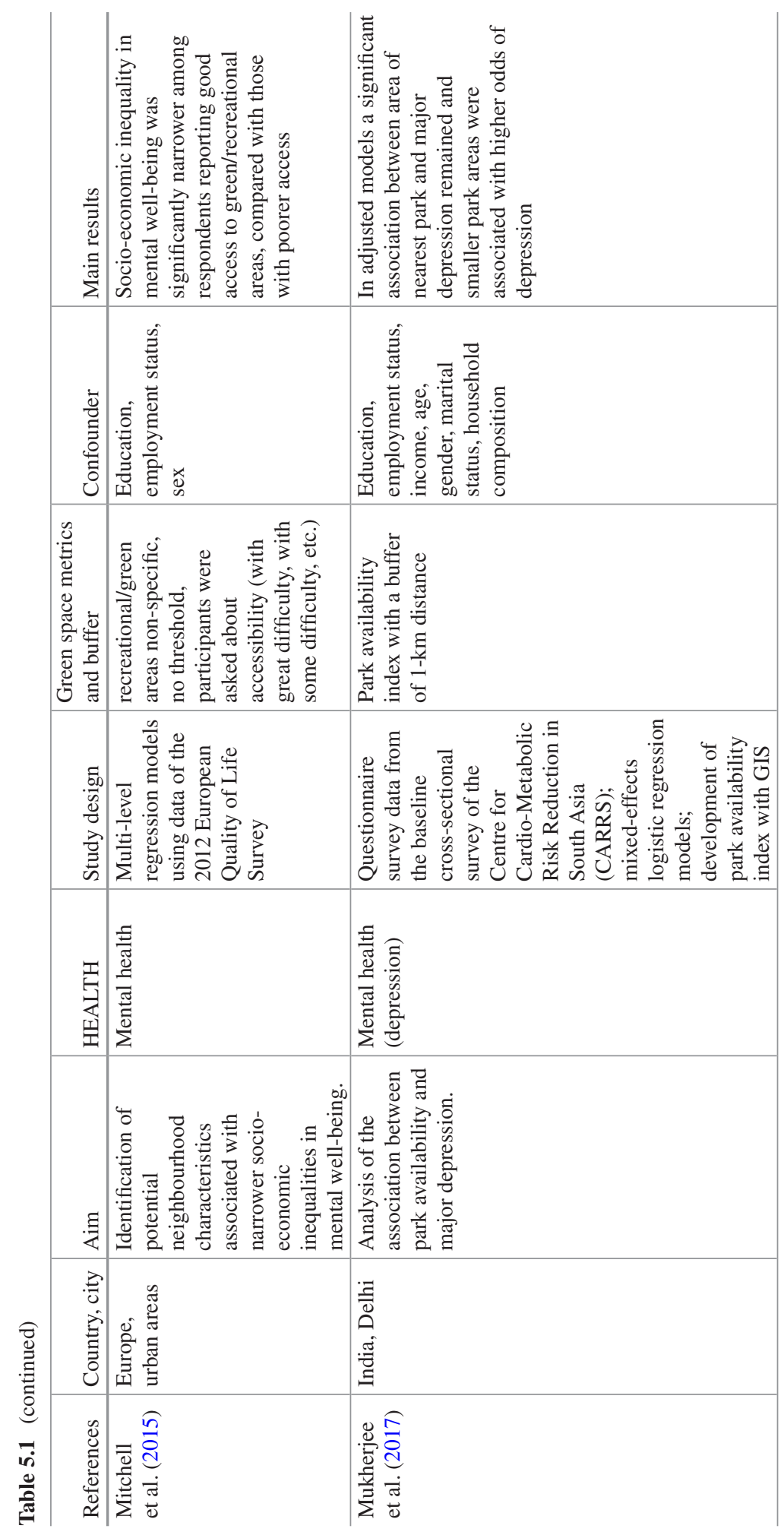




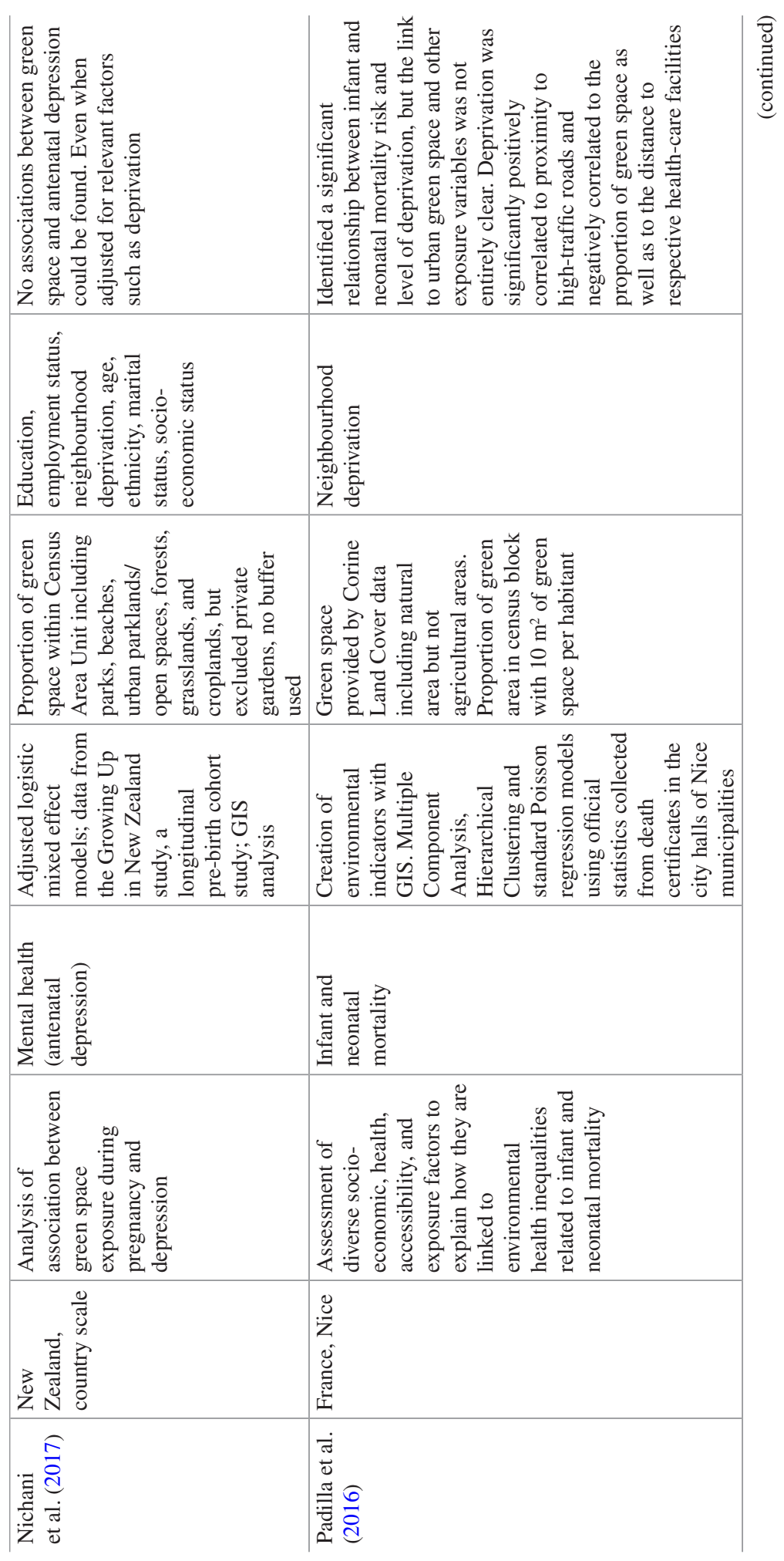




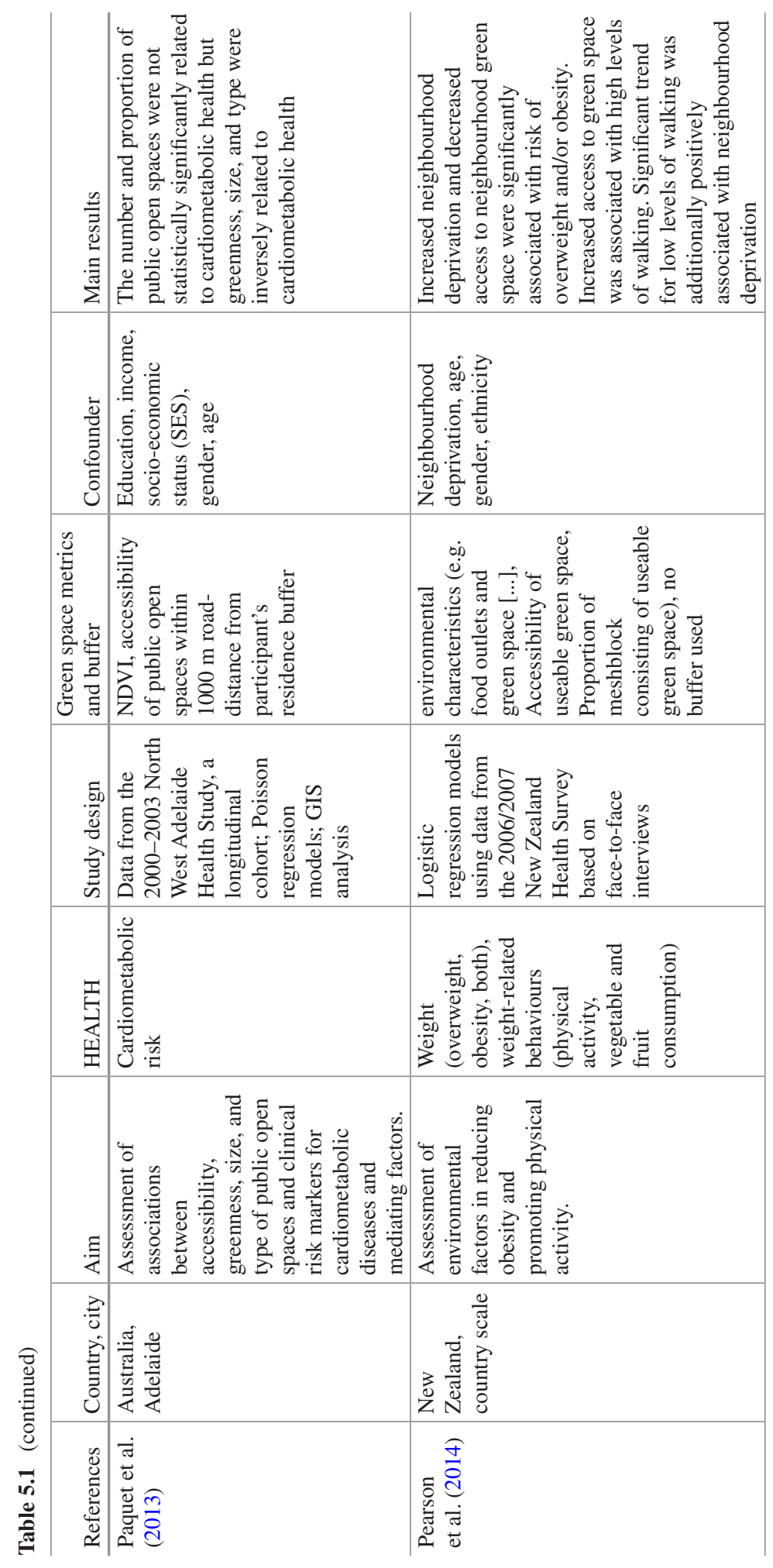




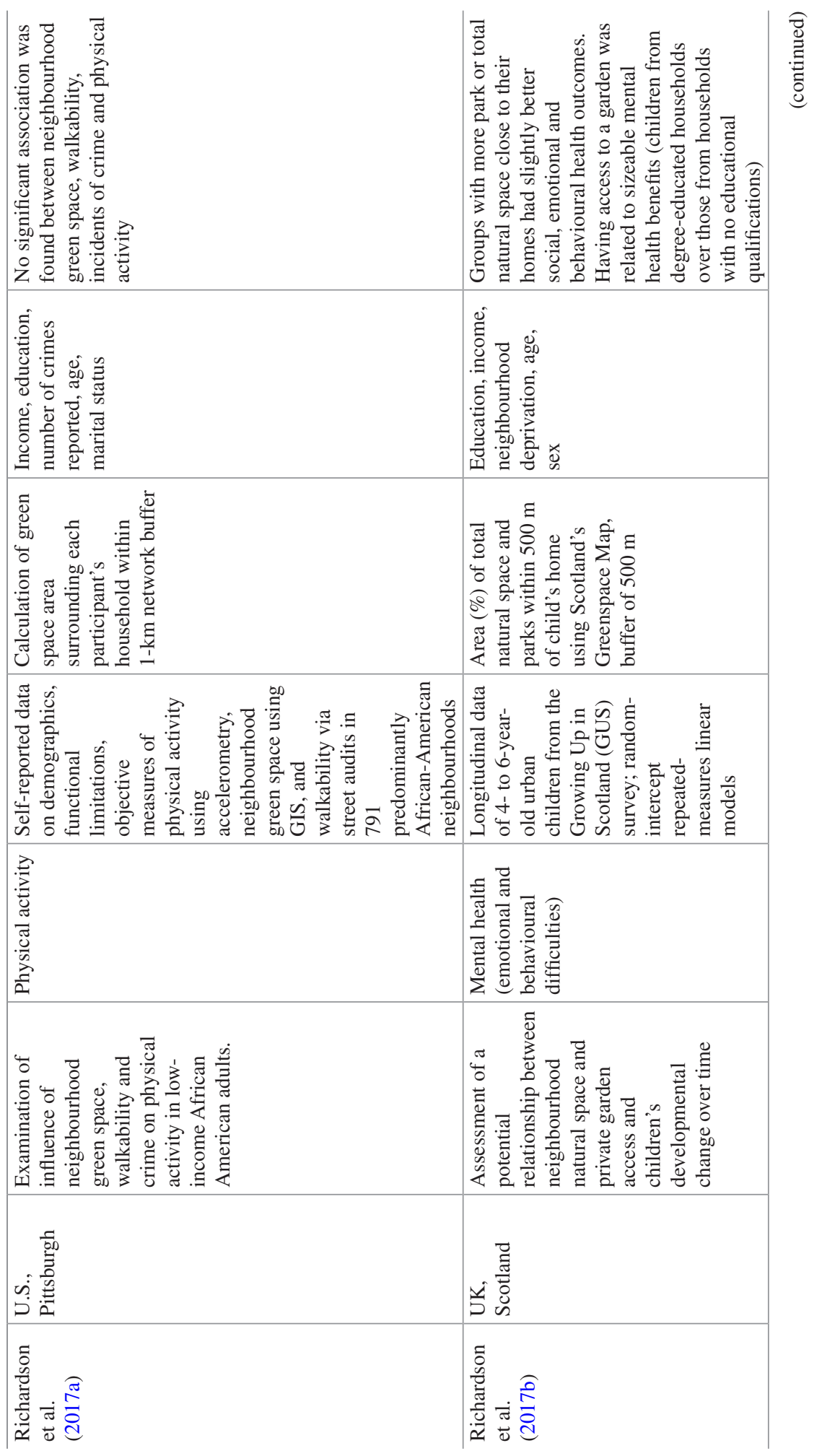




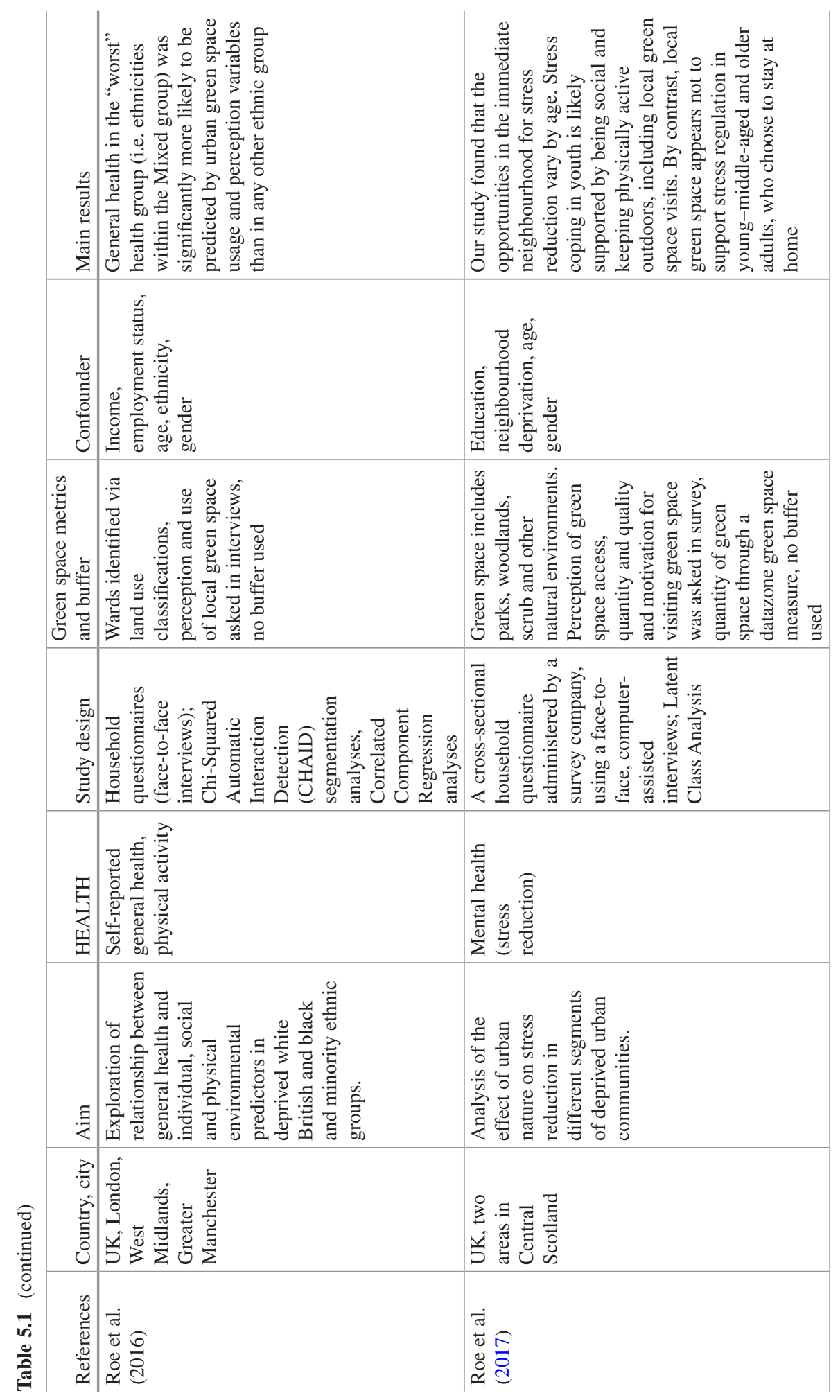




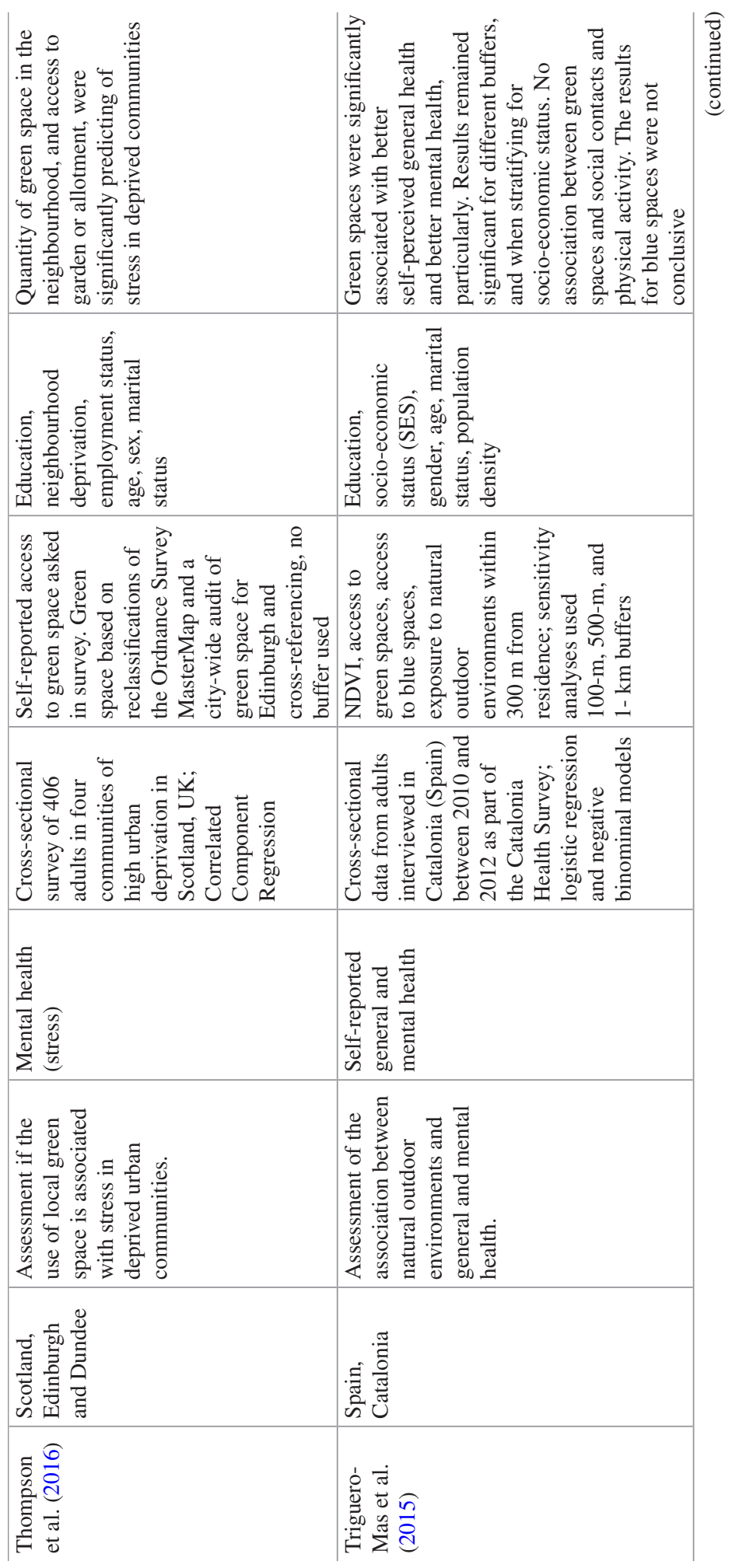




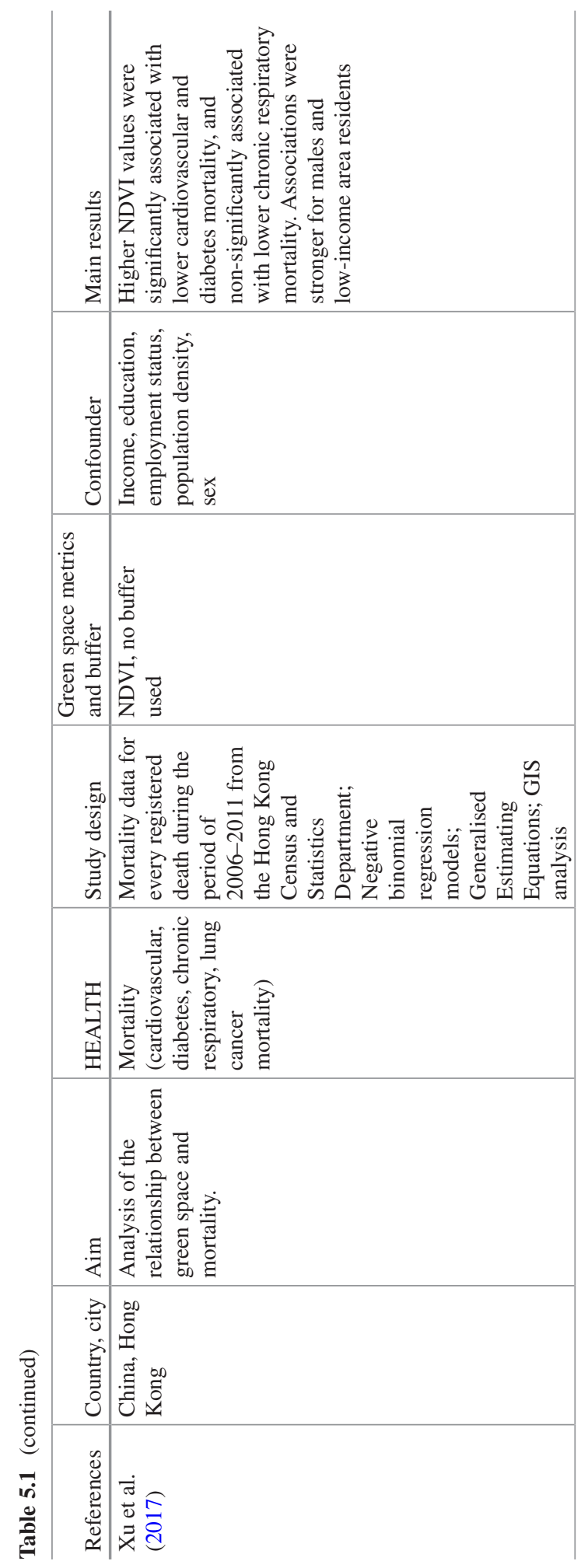


gender. For males, the benefit of green space emerged in early adulthood, while no association was identified for women until later in life. Finally, Nichani et al. (2017) did not identify any associations between green space and depression in pregnant women.

Relatively consistent results show that urban green space has some positive effect on mental health in most age groups, in particular for children, but also for different deprived groups. The effect mostly remained even after controlling for socio-economic confounders such as SES, area deprivation, household income or educational status.

\subsubsection{Birth Outcome}

Abelt and McLafferty (2017) found no consistent significant relationship between birth outcomes and residential greenness. They did, however, identify an inverse relationship between street-level vegetation (street trees) and odds of preterm birth, which remained after controlling for the mother's socio-economic status. Adverse birth outcomes, such as preterm birth or low birth weight, were generally higher among women residing in deprived areas. These deprived areas were less green and had lower numbers of street trees. Similar inconsistencies in results were identified by Cusack et al. (2017). They could not show significant associations between green space and birth weight in full models that take confounders such as ethnicity into account. They did, however, find some consistent associations for the high density urban areas and green space measured at small buffer distances. Adjusted models showed that parents' race/ethnicity had the strongest influence on model predictions, whereas the inclusion of environmental confounders such as $\mathrm{NO}_{2}$ and air pollution had no effect on the NDVI and birth-weight association (see also Dadvand et al. Chap. 6, this volume). Kihal-Talantikite et al. (2013) also included deprivation as a confounding variable to greenness, and showed that there was no difference in the results for infant mortality. Nevertheless, infant mortality rates were not randomly distributed over the study area, showing that both greenness and deprivation may have an impact. Padilla et al. (2016) could not identify a significant association between neonatal mortality and urban green-space exposure. Kihal-Talantikite et al. (2013) and Padilla et al. (2016) found a significant association between neonatal mortality risk and level of deprivation.

Clearly, there is a major link between socio-economic status or deprivation and birth outcomes. Only some studies could show a relationship with urban green space. 


\subsubsection{Overweight}

Three of the reviewed studies have researched the link between green space availability and overweight or obesity in urban areas. Pearson et al. (2014) showed that deprivation and decreased access to green space in the neighbourhood were both significantly linked with higher odds of being overweight or obese. However, for a sample of older women, Michael et al. (2014) could not identify any association with overweight or body mass index (BMI) and changes in the urban environment through, for example, green-space improvements. They did, however, as shown above, again identify a link between being overweight and socio-economic status. A higher socio-economic status of the neighbourhood was associated with a healthier BMI value. Jenkin et al. (2015) found unexpected results, in that more green space in the neighbourhood was associated with lower sugar consumption values. As shown, they also found neighbourhood deprivation to be significantly linked to obesity-related behaviours such as fast-food consumption.

The link between lower socio-economic status and risk of being overweight was identified in the presented studies, whereas the association with urban green space was only identified in one study.

\subsubsection{Physical Activity, Cardiovascular Disease and Mortality}

Recent research suggests that urban green space is associated with participation in physical activity and has, through this, a positive effect on health (see also Dadvand et al. Chap. 6 and Cook et al. Chap. 11, both this volume). McMorris et al. (2015) showed that residents living in areas with the highest share of green space were significantly more likely to be physically active during leisure-time. This relationship appeared in all income groups. Likewise, Pearson et al. (2014) showed that increased access to urban green space was directly associated with higher levels of walking. Low levels of walking were significantly positively associated with neighbourhood deprivation. By contrast, Richardson et al. (2017a) found no significant relationship between physical activity and neighbourhood green space in lowincome African-American adults in a US city.

Paquet et al. (2013) showed that larger, greener and more locally available green spaces in particular were associated with better cardiometabolic health, which is particularly mediated through physical activity. Xu et al. (2017) showed that greater greenness was significantly associated with lower cardiovascular and diabetes mortality, and non-significantly associated with lower chronic respiratory mortality. Relationships were identified to be stronger for residents living in low-income areas.

Although one study could not find any significant association between physical activity and green space, all other review studies showed that urban residents are more physically active in greener neighbourhoods, although one study highlighted a lower degree of activity in deprived areas. 


\subsubsection{Green Space Metrics, Buffers and Data Used}

A number of studies estimated green space or urban greenness with the average Normalised Difference Vegetation Index (NDVI; Abelt and McLafferty 2017; Cohen-Cline et al. 2015; McMorris et al. 2015; Paquet et al. 2013; Triguero-Mas et al. 2015; Xu et al. 2017). The NDVI is a measure of urban greenness based on remote sensing data.

Others use green space classifications based on land use or land cover data in official statistics (Feda et al. 2015; McMorris et al. 2015; Abelt and McLafferty 2017; Cusack et al. 2017; Mukherjee et al. 2017). Several studies use a distinct distance or buffer size from the residential place ranging from $30 \mathrm{~m}$ to $1000 \mathrm{~m}$ (Cusack et al. 2017; McMorris et al. 2015; Abelt and McLafferty 2017; Mukherjee et al. 2017; Feda et al. 2015). Remaining studies apply land-use and land cover data from official national or local statistics. Here urban green is classified as urban parks, urban woodlands or forest areas. Nearly half of the studies use buffer sizes of $500 \mathrm{~m}$ around a residential place or neighbourhood followed by a $250-\mathrm{m}$ and $300-\mathrm{m}$ distance. Those areas should reflect a walking distance of around $10 \mathrm{~min}$ to the next available green space of a certain size.

In general, it cannot be concluded that the results differ depending on the green space measurement, data or buffer size used (for further discussion, see de Vries and Snep Chap. 8, this volume).

\subsubsection{Confounding Factors}

Many studies researched the relationship between health outcome and urban green space exposure or availability while controlling for confounding factors in their statistical models. The articles selected for our review used a number of different socioeconomic and socio-demographic variables (Figs. 5.2 and 5.3). Socio-economic

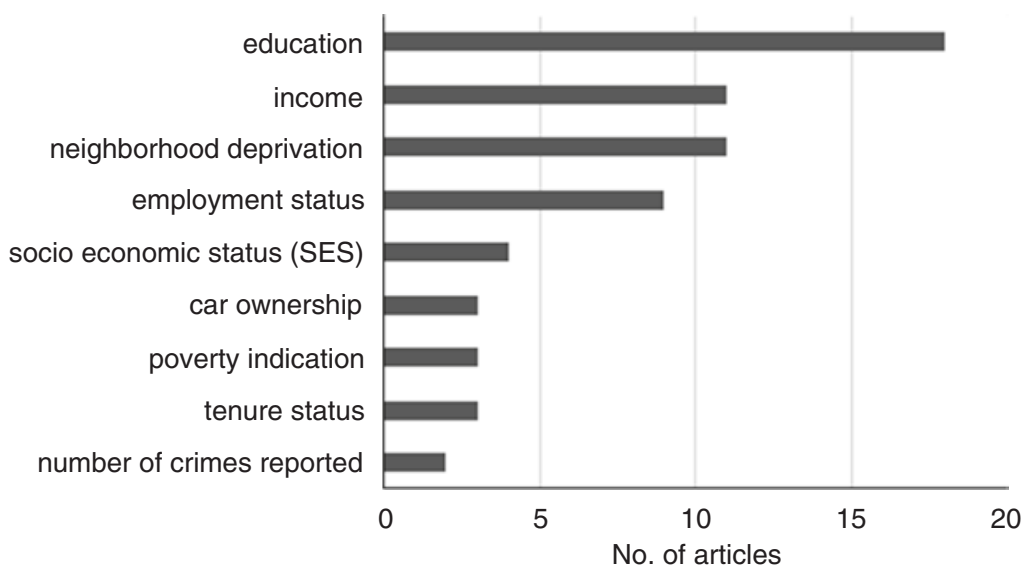

Fig. 5.2 Socio-economic confounders 


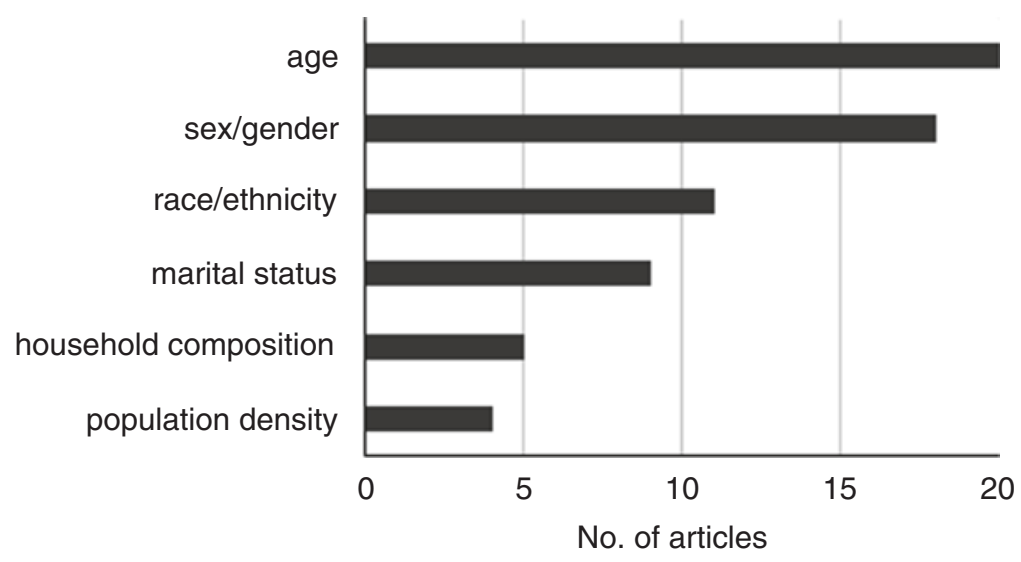

Fig. 5.3 Socio-demographic confounders

confounders mostly address variables of social status that include education of survey participants or households, followed by income or employment status.

For income, it was shown that a higher household income was found to be less likely for residents with psychiatric morbidity, and that this was less prevalent in greener neighbourhoods (Astell-Burt et al. 2014). Significant associations between greenness and physical activity were identified in all income groups (McMorris et al. 2015). Mukherjee et al. (2017) showed that park size was significantly negatively associated with depression even when models were adjusted for confounders such as income, education or employment status, but also for age, gender, marital status and household composition. Similarly, Calogiuri et al. (2016) and Nichani et al. (2017) found that socio-economic inequality in mental well-being was significantly lower among respondents reporting good access to a green space compared with those who had less access. Other studies, however, could not find any relationship between health outcome and socio-economic or socio-demographic confounders (Calogiuri et al. 2016; Nichani et al. 2017) or showed that significant associations between green space and health outcome became non-significant after models were adjusted for confounders (Cusack et al. 2017; Richardson et al. 2017a). For example, Padilla et al. (2016) showed that the significant association between green space and stress disappeared when models were adjusted for socioeconomic confounders. A case study city in France showed a significant relationship between infant and neonatal mortality risk and level of deprivation, but could not clearly explain the link to urban green space (Kihal-Talantikite et al. 2013) (Fig. 5.4). 


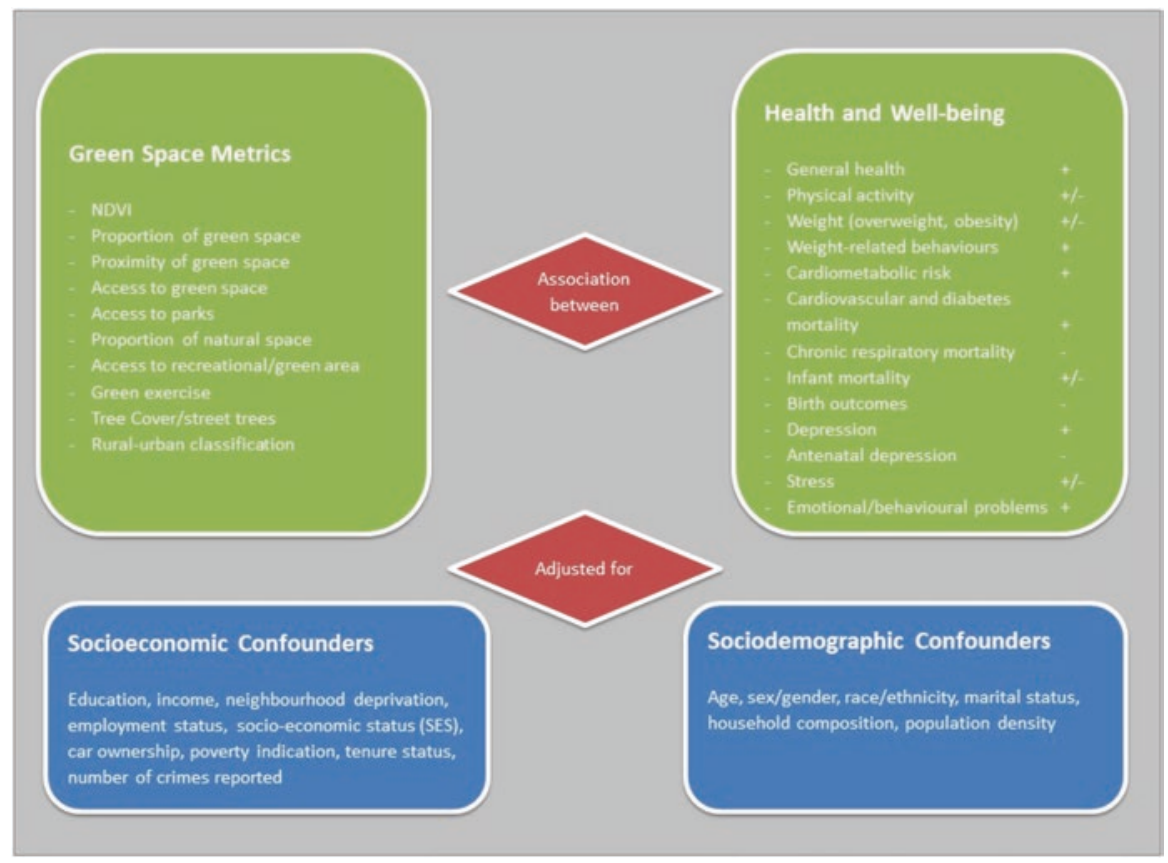

Fig. 5.4 The relationships between urban green space, and health outcomes and confounders, as treated in existing reviews. The strength of the evidence is indicated behind each health outcome: + significant association with evidence, - no signification association found; +/- weak evidence and no consistent results

\subsection{Discussion}

\subsubsection{Urban Green Space and Health Outcomes in Relation to Socio-demographic and Socio-economic Confounders}

This study presents the results of a systematic quantitative review that focuses on the association between green spaces and health outcomes with a particular focus on potential socio-economic and socio-demographic confounding factors. Based on the results of this review, it can be concluded that there is a positive association between urban green space and health outcome variables related to, for example, mental health, birth outcome, general health, overweight and other factors. The most consistent results were identified for the association between urban green space and mental health, in particular for children and adolescents. In a detailed review on the benefits of nature contact for children, Chawla (2015) impressively showed the protective effect of nature for psychological well-being irrespective of the method of measurement. 
In a number of studies, the positive association between urban green space and health outcome remained even after controlling for socio-economic confounders such as SES, area deprivation, household income or educational status. However, associations are not significant in all studies and partly disappeared when statistical models were adjusted for socio-economic and socio-demographic confounding variables. The strongest remaining significance was shown here for mental health and physical activity. A similar conclusion was presented by Kabisch et al. (2017) for an association between urban greenness and health outcome for particular vulnerable groups of children and elderly. Consistent results were also shown for physical activity but not for overweight or obesity. We can conclude that results demonstrate a multi-factor association between socio-economic, socio-demographic and environmental/green factors and potential health outcomes.

Socio-economic and socio-demographic factors are particularly relevant, and often explain health outcomes to a greater extent than green space availability only. Variables that relate to a lower socio-economic status of participants explain more negative health outcomes. However, for mental well-being, inequalities were smaller among urban residents who reported good access to green spaces, compared with those reporting less access. Similar results were also found for health outcome variables other than mental health. Mitchell and Popham (2008) found that, in general, populations that are exposed to the greenest environments were also identified to have the lowest levels of health inequality linked to income deprivation (for further discussion, see Cook et al. Chap. 11, this volume). Further, the mediating effect of urban green space was highlighted for lower income or deprived groups (Flouri et al. 2014; Mitchell et al. 2015; Roe et al. 2017). Some green space and health relationships appeared to be stronger for those living in low-income areas (Xu et al. 2017). The mediating effect of urban green space may be particularly important for lower status groups. Chawla (2014) reported the importance of nature as a green refuge, with particular importance for children in the context of poverty and displacement.

Reasons for some inconsistencies in the results of the potential association between urban green space health outcomes depend on the particular inclusion variables. Some authors suggested that their results are different from other studies because of the non-inclusion of particular confounding factors such as environmental and neighbourhood characteristics of deprivation, crime, air pollution, etc. (Pearson et al. 2014). Furthermore, inconsistencies might be explained by the difference in green space provision in urban areas in different case studies (Richardson et al. 2017a).

\subsubsection{Implications for Urban Policy and Planning}

What can urban planning and policy-making learn from the studies discussed in this review? Goal 11 from the SDGs clearly states that creating green public spaces will be integratively linked to sustainable and safe urban development. But how is a 
green space that is most beneficial for all population groups including the vulnerable groups of children, the elderly and deprived people designed?

In the review, green space assessments were conducted that focus on different types of green space, such as parks, street trees or house gardens. Small-scale urban green space such as tree canopies in cities have been shown to improve health effects such as birth outcome, mortality and restoration (Abelt and McLafferty 2017) (see also Lindley et al. Chap. 2, this volume). Small green spaces such as street trees, paths, greenways or gardens provide effective opportunities for restoration and stress reduction as types of micro-restorative settings (Mitchell et al. 2015; Triguero-Mas et al. 2015). The increase in the number of street trees in an urban neighbourhood and the maintenance of existing trees might be of particular importance in disadvantaged neighbourhoods as this could go hand-in-hand with potential positive effects for environmental justice (Landry and Chakraborty 2009; Abelt and McLafferty 2017). In the study by Cusack et al. (2017), it was shown that an increase in urban green space on smaller scales is particularly important in high density urban areas to improve birth outcomes. Further, a stronger association between green space and lower mortality rates was highlighted for those living in areas with higher population densities (Xu et al. 2017). The authors argue that the beneficial effects of green space, including physical exercise opportunities, pollution and urban heat island reduction, and stress relief, may be more needed among people living in more urbanised settings. To conclude, the implementation and maintenance of small-scale green spaces in the form of trees, but also green space within a 50-m distance, is particularly beneficial in high-density urban areas (Markevych et al. 2014; Casey et al. 2016).

In many articles, the authors pointed to the fact that the availability, accessibility and quality of urban green spaces is important for health benefits (Paquet et al. 2013). The size of the park might be one quality criteria that particularly relates to physical activity and mental health outcomes. It has been argued that larger parks in particular are related to a lower risk of cardiometabolic diseases and greater levels of physical activity, whereas studies that only focus on accessibility distance measures without considering any quality aspect could often not find any significant relationship between health outcomes and urban green space (Michael et al. 2014; Nichani et al. 2017). Mukherjee et al. (2017) found an inverse association between park size and depression. They suggested that large parks in particular may provide more benefits of green space exposure, because in their case study of Delhi, they are better maintained, have more natural spaces and diverse landscapes, and are more frequently visited, which translates into more opportunities to socialise. It can be concluded that the quality and a certain size but also the availability within a certain distance of an urban green space all play a role in motivating individuals to use outdoor spaces for physical activity (Jenkin et al. 2015; Mukherjee et al. 2017). Furthermore, the review results showed how green spaces equipped with playgrounds, sport areas, benches, toilets, lights, trees to provide shade, and good sidewalk quality and connectivity can play a more important role in green space use for health and well-being and should be considered in urban planning and decisionmaking (Michael et al. 2014). Particularly for children, green spaces provide places 
to explore, play, discover and engage with nature, all important resources for mental well-being (Chawla 2015). This calls for green spaces that are not perfectly manicured but include diverse components of green such as adventure areas, wilderness areas, playgrounds, amongst others. This has been achieved in the development of the park 'Gleisdreieck' in the inner city area of Berlin, where local residents also took an active role in shaping and planning their local green space (Kabisch 2015; Rall et al. 2015).

With regard to the social and socio-economic context criteria, Richardson et al. (2017a, b) showed that children from low-education households had significantly less natural space in their neighbourhoods, and McMorris et al. (2015) found significant relationships between greenness and physical activity for all income groups. Increasing levels of greenness do therefore benefit all population groups, which should be taken into consideration in urban planning for future green space development and maintenance (Cook et al. Chap. 11, Davies et al. Chap. 12, and Heiland et al. Chap. 19, all this volume). Roe et al. (2016) highlighted the fact that particular patterns of use of urban green spaces differ significantly according to different ethnic and gender groups and needs to be considered by planners and policy-makers in a way to steer green space provision appropriately. This suggests that developing new green spaces needs to consider the local context carefully and sensitively.

Safety plays a major role in green space use. Urban green space might be available in significant quantity but is not used by the residential population because of safety concerns (Cohen et al. 2010). Perceived safety concerns and poor environmental quality of local green spaces may discourage residents from using these spaces (Dadvand et al. Chap. 6, this volume). Policy-makers and urban planners should act in these instances to make areas safer and decrease environmental pollution.

\subsubsection{Directions for Future Research}

Several studies have discussed that exposure and use of urban green space differs according to social and demographic background. Astell-Burt et al. (2014) discussed that exposure to green space varies in different stages in life and that these differences manifest in health disparities. People of different age groups may have different needs with regard to urban green spaces, which in turn translates into diverse health outcome effects (Roe et al. 2017). McMorris et al. (2015) identified an age-specific relationship to green space use for physical activity with significant results for associations between younger adults and women and lower associations with increasing age. In addition, Roe et al. (2017) showed that the use of green space and perception of green space quality does not only vary by age group but also by deprivation: Whilst younger people (youth) are using nearby green space 
regularly and are satisfied with its quality, the same (or similar) outdoor space is not supporting the needs of young to middle-aged adults. The authors showed that judgements about the quality aspects of urban green space vary across age groups, but place more importance on utilising green space than either on the size of green space or on proximity. Understanding how all these attributes interact and translate into health outcomes is one direction for future research.

Interestingly, results of only two studies were based on objective health measurements (Michael et al. 2014 through clinical examination for detecting obesity; Richardson et al. 2017a using accelerometry for detecting physical activity). All other studies under review used secondary data from official statistics or data from health questionnaires where respondents reported their health status themselves, mostly through well-developed Likert scale measurements for perceived health. In the two studies using objective measures, no consistent association between health and urban green space was identified. One could argue that objectively measured health is the most reliable because it might be less biased by indirect indicators or perceptions. There are, however, other studies that use objective measures to assess potential links between stress levels and urban green space, e.g. through cortisol levels or electroencephalography (Ward Thompson et al. 2012; Aspinall et al. 2013). In these studies, stress levels were found to decrease in greener environments. Stress levels, however, always depend on many different aspects that may lead to an increase or decrease in stress levels. A combination of both subjective and objective measurements is an important field for future research.

Focus on the method of measurement is worth discussing here. All studies used and produced quantitative data and conducted statistical analyses. The review showed that important results were produced from this approach. No study in this review used qualitative research methods, such as an ethnographic approach that includes assessments of observing free behaviour. For children of a particular age group, Chawla (2015) pointed out that ethnographic approaches show how green space can contribute to the development of children's capabilities and to their "complete physical, mental and social well-being". Echoing Chawla (2015), future research should combine qualitative and quantitative approaches that include ethnographic assessment (see Kabisch and Haase 2014; Low 2013 for further details), but also experimental and correlational methods that, when used together, may increase the understanding of health and the environment.

The selection of particular search terms for the review has, of course, produced somewhat narrow results. Using other search terms may have contributed to a larger evidence base on the urban green space-health outcome association, e.g. through increasing the scope to other types of nature, such as trees. However, the focus of this review was to look at potential confounding factors that may explain health-outcome results, and to urban green spaces as a broad group of urban nature. Further, by limiting the review to recent studies, older studies are omitted, although they certainly are as important to review and discuss, especially as they relate to confounding variables. 


\subsection{Conclusion}

Research studies on the association between urban green space and health shows that availability, proximity and use of urban green space such as parks or even allotment gardens, helps to improve the mental health of urban residents even when controlling for socio-economic or socio-demographic confounders. Studies that focus on other health outcomes, such as overweight or birth outcomes, show that significant relationships partly disappear when statistical models are adjusted for socio-economic variables. Income, deprivation or education are amongst the most important variables that confound the green space-health-outcome relationship. Nevertheless, a mediating role of urban green space for socio-economic inequality in health outcome was identified. The results have led to important planning recommendations and directions for future research, which have been presented and discussed here.

This area of research is gaining widespread attention through the promotion of the Sustainable Development Goals and related larger project financing, considering recent calls under the European Commission Research and Innovation Programme. A number of important studies are expected to be conducted in the near future.

Acknowledgments This work was supported by the project "Environmental-health Interactions in Cities (GreenEquityHEALTH) - Challenges for Human Well-being under Global Changes" (2017-2022) funded by the German Federal Ministry of Education and Research (BMBF) (funding code: 01LN1705A).

\section{References}

Abelt K, McLafferty S (2017) Green streets: urban green and birth outcomes. Int J Environ Res Public Health 14(7). https://doi.org/10.3390/ijerph14070771

Allan R, Williamson P, Kulu H (2017) Unravelling urban-rural health disparities in England. Popul Space Place 23(8):e2073. https://doi.org/10.1002/psp.2073

Aspinall $\mathrm{P}$ et al (2013) The urban brain: analysing outdoor physical activity with mobile EEG. Br J Sports Med 1. https://doi.org/10.1136/bjsports-2012-091877

Astell-Burt T, Mitchell R, Hartig T (2014) The association between green space and mental health varies across the lifecourse. A longitudinal study. J Epidemiol Community Health 68(6):578583. https://doi.org/10.1136/jech-2013-203767

Bowler DE et al (2010) Urban greening to cool towns and cities: a systematic review of the empirical evidence. Landsc Urban Plann Elsevier B.V. 97(3):147-155. https://doi.org/10.1016/j. landurbplan.2010.05.006

Calogiuri G, Patil GG, Aamodt G (2016) Is green exercise for all? A descriptive study of green exercise habits and promoting factors in adult Norwegians. Int J Environ Res Public Health 13(11). https://doi.org/10.3390/ijerph13111165

Casey JA et al (2016) Greenness and birth outcomes in a range of Pennsylvania communities. Int J Environ Res Public Health 13(3). https://doi.org/10.3390/ijerph13030311 
Chawla L (2014) Children's engagement with the natural world as a ground for healing. In: Krasny ME, Tidball GG (eds) Greening in the red zone: disaster, resilience and community greening. Springer, Heidelberg, pp 111-124

Chawla L (2015) Benefits of nature contact for children. J Plan Lit 30(4):433-452. https://doi. org/10.1177/0885412215595441

Clark LP, Millet DB, Marshall JD (2014) National patterns in environmental injustice and inequality: outdoor NO2 air pollution in the United States. PLoS One 9(4):e94431. https://doi. org/10.1371/journal.pone.0094431

Cohen DA et al (2010) Parks and physical activity: why are some parks used more than others? Prevent Med Elsevier Inc 50(SUPPL):S9-S12. https://doi.org/10.1016/j.ypmed.2009.08.020

Cohen-Cline H, Turkheimer E, Duncan GE (2015) Access to green space, physical activity and mental health: a twin study. J Epidemiol Commun Health. Department of Epidemiology, School of Public Health, University of Washington, Seattle, Washington, USA: BMJ Publishing Group. https://doi.org/10.1136/jech-2014-204667

Cusack L et al (2017) Associations between multiple green space measures and birth weight across two US cities. Health Place 47:36-43. https://doi.org/10.1016/j.healthplace.2017.07.002

Díaz S et al (2018) Assessing nature's contributions to people. Science 359(6373):270-272. https://doi.org/10.1126/science.aap8826

Feda DM et al (2015) Neighbourhood parks and reduction in stress among adolescents: results from Buffalo, New York. Indoor Built Environ 24(5):631-639. https://doi.org/10.1177/1420 $326 X 14535791$

Flouri E, Midouhas E, Joshi H (2014) The role of urban neighbourhood green space in children's emotional and behavioural resilience. J Environ Psychol 40:179-186. https://doi.org/10.1016/j. jenvp.2014.06.007

Haase D et al (2014) A quantitative review of urban ecosystem service assessments: concepts, models, and implementation. AMBIO 43(4):413-433. https://doi.org/10.1007/s13280-014-0504-0

Hartig T et al (2014) Nature and health. Annu Rev Public Health 35:207-228. https://doi. org/10.1146/annurev-publhealth-032013-182443

Jenkin GL et al (2015) Neighbourhood influences on children's weight-related behaviours and body mass index. AIMS Public Health 2(3):501-515. https://doi.org/10.3934/ publichealth.2015.3.501

Kabisch N (2015) Ecosystem service implementation and governance challenges in urban green space planning-the case of Berlin, Germany. Land Use Policy Elsevier Ltd 42:557-567. https:// doi.org/10.1016/j.landusepol.2014.09.005

Kabisch N, Haase D (2014) Green justice or just green? Provision of urban green spaces in Berlin, Germany. Landscape and Urban Planning. Institute of Geography, Humboldt Universität zu Berlin, Unter den Linden 6, 10099 Berlin, Germany 122:129-139. https://doi.org/10.1016/j. landurbplan.2013.11.016

Kabisch N, van den Bosch M, Lafortezza R (2017) The health benefits of nature-based solutions to urbanization challenges for children and the elderly - a systematic review. Environ Res 159(January):362-373. https://doi.org/10.1016/j.envres.2017.08.004

Kihal-Talantikite W, Padilla CM, Lalloué B et al (2013) Green space, social inequalities and neonatal mortality in France. BMC Preg Childbirth 13:191. https://doi. org/10.1186/1471-2393-13-191

Landry SM, Chakraborty J (2009) Street trees and equity: evaluating the spatial distribution of an urban amenity. Environ Plan A 41:2651-2670

Low S (2013) Public space and diversity: distributive, procedural and interactional justice for parks. In: Young G, Stevenson D (eds) The Ashgate research companion to planning and culture. Ashgate Publishing, Surrey, pp 295-310

Markevych I et al (2014) A cross-sectional analysis of the effects of residential greenness on blood pressure in 10-year old children: results from the GINIplus and LISAplus studies. BMC Public Health. Institute of Epidemiology i, Helmholtz Zentrum München, German Research Centre 
for Environmental Health, Ingolstädter Landstr, 1, 85764 Neuherberg, Germany: BioMed Central Ltd. 14(1). https://doi.org/10.1186/1471-2458-14-477

McMorris $\mathrm{O}$ et al (2015) Urban greenness and physical activity in a national survey of Canadians. Environ Res 137:94-100. https://doi.org/10.1016/j.envres.2014.11.010

Michael YL et al (2014) Does change in the neighborhood environment prevent obesity in older women? Soc Sci Med 102:129-137. https://doi.org/10.1016/j.socscimed.2013.11.047

Mitchell R, Popham F (2008) Effect of exposure to natural environment on health inequalities: an observational population study. Lancet 372(9650):1655-1660. https://doi.org/10.1016/ S0140-6736(08)61689-X

Mitchell RJ et al (2015) Neighborhood environments and socioeconomic inequalities in mental Well-being. Am J Prev Med 49(1):80-84. https://doi.org/10.1016/j.amepre.2015.01.017

Mukherjee D et al (2017) Park availability and major depression in individuals with chronic conditions: is there an association in urban India? Health Place 47:54-62. https://doi.org/10.1016/j. healthplace.2017.07.004

Nichani V et al (2017) Green space and depression during pregnancy: results from the growing up in New Zealand study. Int J Environ Res Public Health 14(9). https://doi.org/10.3390/ ijerph14091083

Padilla CM et al (2016) Use of geographic indicators of healthcare, environment and socioeconomic factors to characterize environmental health disparities. Environ Health 15(1):79. https://doi.org/10.1186/s12940-016-0163-7

Paquet $C$ et al (2013) Are accessibility and characteristics of public open spaces associated with a better cardiometabolic health? Landsc Urban Plan 118:70-78. https://doi.org/10.1016/j. landurbplan.2012.11.011

Pearson AL et al (2014) Associations between neighbourhood environmental characteristics and obesity and related behaviours among adult New Zealanders. BMC Public Health 14. https:// doi.org/10.1186/1471-2458-14-553

Rall EL, Kabisch N, Hansen R (2015) A comparative exploration of uptake and potential application of ecosystem services in urban planning. Ecosys Ser Elsevier:1-13. https://doi. org/10.1016/j.ecoser.2015.10.005

Raymond CM, Berry P, Breil M, Nita MR, Kabisch N, de Bel M, Enzi V, Frantzeskaki N, Geneletti D, Cardinaletti M, Lovinger L, Basnou C, Monteiro A, Robrecht H, Sgrigna G, Munari L, Calfapietra C (2017) An impact evaluation framework to support planning and evaluation of nature-based solutions projects. Report prepared by the EKLIPSE expert working group on nature-based solutions to promote climate resilience in urban areas. Centre for Ecology \& Hydrology, Wallingford, United Kingdom

Richardson EA et al (2013) Particulate air pollution and health inequalities: a Europe-wide ecological analysis. Int J Health Geogr 12(1):34. https://doi.org/10.1186/1476-072X-12-34

Richardson AS et al (2017a) One size doesn't fit all: cross-sectional associations between neighborhood walkability, crime and physical activity depends on age and sex of residents. BMC Public Health 17. https://doi.org/10.1186/s12889-016-3959-z

Richardson EA et al (2017b) The role of public and private natural space in children's social, emotional and behavioural development in Scotland: a longitudinal study. Environ Res 158:729736. https://doi.org/10.1016/j.envres.2017.07.038

Rigolon A (2016) A complex landscape of inequity in access to urban parks: a literature review. Landsc Urban Plan 153:160-169. https://doi.org/10.1016/j.landurbplan.2016.05.017

Roe J, Aspinall PA, Thompson CW (2016) Understanding relationships between health, ethnicity, place and the role of urban green space in deprived urban communities. Int J Environ Res Public Health 13(7). https://doi.org/10.3390/ijerph13070681

Roe JJ, Aspinall PA, Thompson CW (2017) Coping with stress in deprived urban neighborhoods: what is the role of green space according to life stage? Front Psychol 8. https://doi.org/10.3389/ fpsyg.2017.01760 
The United Nations Development Programme (UNDP) (2015) Sustainable development goals: introducing the 2030 agenda for sustainable development. Available at: file:///C:/iDiv/orga/ Anträge/ESCALATE/SDGs_Booklet_Web_En.pdf

Thompson CW et al (2016) Mitigating stress and supporting health in deprived urban communities: the importance of green space and the social environment. Int J Environ Res Public Health 13(4). https://doi.org/10.3390/ijerph13040440

Timperio A et al (2007) Is availability of public open space equitable across areas? Health Place 13(2):335-340. https://doi.org/10.1016/j.healthplace.2006.02.003

Triguero-Mas $\mathrm{M}$ et al (2015) Natural outdoor environments and mental and physical health: relationships and mechanisms. Environ Int 77:35-41. https://doi.org/10.1016/j.envint.2015.01.012

van den Bosch M, Ode Sang Å (2017) Urban natural environments as nature-based solutions for improved public health - a systematic review of reviews. Environ Res 158:373-384. https:// doi.org/10.1016/j.envres.2017.05.040

Ward Thompson C et al (2012) More green space is linked to less stress in deprived communities: evidence from salivary cortisol patterns. Landsc Urban Plann Elsevier BV 105(3):221-229. https://doi.org/10.1016/j.landurbplan.2011.12.015

Wolch J, Wilson J, Fehrenbach J (2005) Parks and park funding in Los Angeles: an equity-mapping analysis. Urban Geogr 26(1):4-35. https://doi.org/10.2747/0272-3638.26.1.4

Wolch JR, Byrne J, Newell JP (2014) Urban green space, public health, and environmental justice: the challenge of making cities "just green enough". Landsc Urban Plann Elsevier BV 125:234-244. https://doi.org/10.1016/j.landurbplan.2014.01.017

$\mathrm{Xu} \mathrm{L}$ et al (2017) An ecological study of the association between area-level green space and adult mortality in Hong Kong. Climate 5(3). https://doi.org/10.3390/cli5030055

Open Access This chapter is licensed under the terms of the Creative Commons Attribution 4.0 International License (http://creativecommons.org/licenses/by/4.0/), which permits use, sharing, adaptation, distribution and reproduction in any medium or format, as long as you give appropriate credit to the original author(s) and the source, provide a link to the Creative Commons license and indicate if changes were made.

The images or other third party material in this chapter are included in the chapter's Creative Commons license, unless indicated otherwise in a credit line to the material. If material is not included in the chapter's Creative Commons license and your intended use is not permitted by statutory regulation or exceeds the permitted use, you will need to obtain permission directly from the copyright holder.

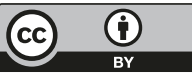

